JASEM ISSN 1119-8362

All rights reserved
Full-text Available Online at http:// www.bioline.org.br/ja
J. Appl. Sci. Environ. Mgt. 2004

Vol. 8 (2) 19 - 22

\title{
Effect of Size on the Acute Toxicity of Crude Oil to the Mangrove Oyster, Carasostrea gasar
}

\author{
*DAKA, E R; EKWEOZOR, I K E \\ Department of Biological Sciences, Rivers State University of Science and Technology, P. M. B. 5080, Port Harcourt, Nigeria. \\ Email: eremadaka@yahoo.com
}

\begin{abstract}
The acute toxic effects of a Nigerian crude oil (Egbogoro Liner II) to the mangrove oyster Crassostrea gasar were studied in bioassays. Tests were conducted over a 96-hr period after acclimatization of individuals in the laboratory, initially with a population comprising a broad size categories $(11-60 \mathrm{~mm})$ in range finding tests. The tests were semi-static bioassays in which the exposure media were replaced every 24 hours, at which the oysters were also examined for mortality. Subsequent experimentation was designed to compare the toxicities of oil to small $(10-30 \mathrm{~mm})$ and large $(41-60 \mathrm{~mm})$ oysters. LC $_{50}$ values were obtained by graphical interpolation. Significant differences in effects at each time interval between small and large oysters were determined using the Man-Whitney tests on percentage mortality values. Relative toxicity tests showed consistently lower mortalities for small oysters at 24-hr, 48-hr and 96-hr periods, with Mann-Withney tests showing significant differences $(\mathrm{p}<0.05)$ in mortality in 48 and $96 \mathrm{hr}$ bioassays. The 96-hr $\mathrm{LC}_{50}$ value for the larger oysters (135 ppm) was lower than that of the smaller ones (545 ppm), implying that smaller oysters (in the size ranges used) were more tolerant to crude oil than the larger ones. @JASEM
\end{abstract}

Acute toxicity tests or bioassays have historically played an important role in assaying the effects of human activities on animals, and such tests have wide applicability when evaluating the toxicities of various types and mixtures of pollutants to fish and other aquatic species (Craddock, 1977). The parameter of short-term mortality has been the most common measure of toxicity (Cowell et al., 1972; Krebs and Burns, 1977). A variety of marine invertebrates have been examined to test the lethal effects of several toxicants on aquatic biota. The effect of exploration and production activities of the oil industry on the Nigerian environment has been the cause of great concern in recent times. Since the early 1970s studies have been carried out on the effects of crude oil, with the initial ones concentrating on effects on land and aquatic environment with special emphasis on microorgansms and the degradation of oil by these organisms (Odu, 1981). Relatively few studies have been conducted on toxicity of oil to local estuarine fauna (Ajao et al., 1981). More recent acute toxicity tests of Nigerian crude oils were carried out by Afolabi et al. (1985) and Eco-Development Consultancy Group (Odiete, 1999); these studies concentrated on fish and crustaceans

The present study examines the toxicity of Nigerian crude oil to the local marine and estuarine species. Acute toxicity tests were carried out using the mangrove oyster Crassostra gasar. C. gasar (a bivalve mollusc) was chosen because of its ready availability, economic and ecological importance. The median lethal concentration $\left(\mathrm{LC}_{50}\right)$ of oysters to Nigerian crude oil was investigated in 24-hr, 48-hr and 96-hr static bioassays. The size of invertebrates could have an influence on the toxic effects of pollutants. It was therefore decided to study the effect of the size of oysters on the toxicity of crude oil.

\section{MATERIALS AND METHODS}

The oysters for the study were collected near Tombia in the Degema Local Government Area of Rivers State, Nigeria. The prop roots on which the oysters settled were cut off during the low tide period when they were uncovered by the tides. The oysters (along with the prop roots) were transported to the laboratory where individuals were removed from the props. Care was taken to ensure that the oysters were not damaged during removal from the prop roots; undamaged individuals were acclimatized to laboratory conditions for three days in brackish water before use in the bioassays. The shell lengths of the oysters were measured using a calliper square. The bioassay units comprised of rectangular glass aquaria (32 cm x $21 \mathrm{~cm} \times 19.5 \mathrm{~cm}$ ) holding $5000 \mathrm{ml}$ of test media. Aeration was provided by gently bubbling air through disposable Pasteur pipettes connected via plastic tubes to an air pump. The brackish water used for the experiments was collected from the creek at which the oysters were obtained.

For each experiment 20 individuals of the desired shell lengths were placed in each test chamber for acclimatization. During the three-day acclimatization period, oysters were observed and any dead ones were replaced with individuals from the stock retained in a different aquarium. A preliminary (range finding) experiment was conducted using broad size classes of oysters and a wide range of

*Corresponding author

Email: eremadaka@yahoo.com 
concentrations of crude oil. Twenty individuals spread evenly in five size classes (11-20 mm; 21-30 $\mathrm{mm}$; $31-40 \mathrm{~mm}$; $41-50 \mathrm{~mm}, 51$ to $60 \mathrm{~mm}$ ) were placed in each test chamber. The concentrations of crude oil (Egbogoro liner II) used were $0.1 \mathrm{pm}, 1$ ppm, 10 ppm, 100 ppm, 500 ppm and 1000 ppm. Nominal test concentrations were made up (vol. $\mathrm{x}$ vol.) by mixing crude oil with appropriate volumes of estuarine water (Odiete, 1999). A control tank with no oil added was also set up. The test populations were observed after 24 hours, 48 hours and 96 hours. On each occasion, all dead oysters were removed and their numbers recorded. Dead oysters were those that did not exhibit shell closure in response to tactile stimulation (being prodded with a blunt probe).

The main experiments were comparative bioassays to assess the effects of size on mortality of oysters. Two size classes were used; large (41 - $60 \mathrm{~mm})$ and small $(10-30 \mathrm{~mm})$. For each experiment twenty individuals of each size class was utilized. Experimental protocols are as described above, with concentrations chosen on the basis of data from the preliminary experiments. Mortalities recorded were expressed as percentages of the test populations and the median lethal concentration was estimated by graphical interpolations. In order to test for significant differences in the mortality profiles between the different size classes, Mann-Whitney tests (Zar, 1984) were conducted, using the MINITAB for Windows statistical software.

\section{RESULTS AND DISCUSSION}

The results of the preliminary experiment showing the population response of a wide size range of oysters (11 to $60 \mathrm{~cm}$ ) are presented in Fig. 1. After 24-hr exposure, mortalities were only observed at $500 \mathrm{ppm}$ and $1000 \mathrm{ppm}$ with a maximum of $20 \%$; implying that the 24-hr LC50 is outside the range of concentrations utilized for the experiments. Mortalities were similarly only recorded at $500 \mathrm{ppm}$ and 1000 ppm after 48 hrs but in this case mortalities were $>50 \%$. Exposures over a 96-hr period resulted in mortalities of 4\%, $95 \%$ and $100 \%$ mortality respectively at $100 \mathrm{ppm}, 500 \mathrm{ppm}$ and $1000 \mathrm{ppm}$.

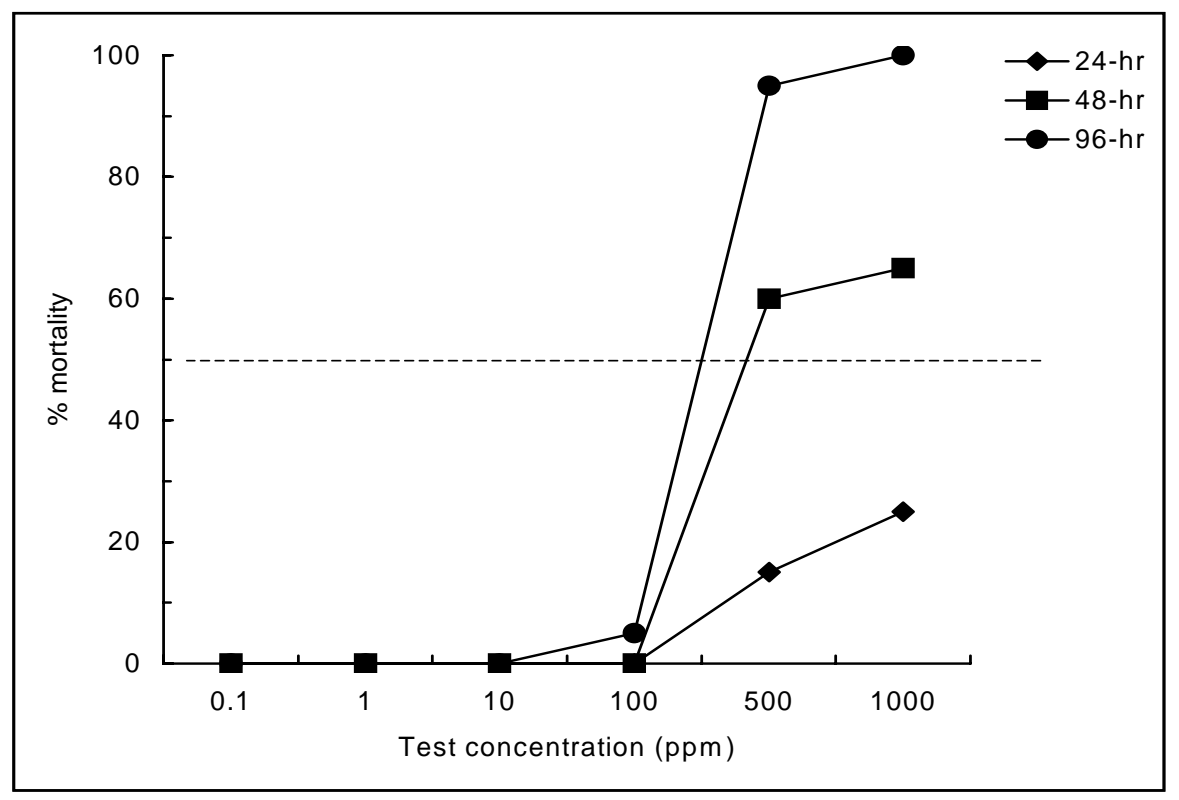

Fig. 1. Mortalities (\%) of broad size classes $(10-60 \mathrm{~cm})$ of oysters (Crassostrea gasar) exposed to wide concentration range of crude oil over a 96-hr period.

Figure 2 is a presentation of the comparative mortality profiles of large and small oysters. Data for the 24-hr exposure period showed minimal mortalities (Fig. 2a), indicating consistently higher effects on large oysters than the small ones. However, Mann-Whitney test did not show any significant difference $(\mathrm{p}=0.08)$. Mortalities after 48 hrs were also higher for the large oysters with $>50 \%$ mortality recorded at 600 and 800 ppm (Fig. 2b), whereas the highest mortality of $30 \%$ was recorded at $800 \mathrm{ppm}$ for the small oysters. Mann-Whittney test showed significant differences $(\mathrm{p}<0.05)$ in toxic effects between large and small oysters after 48-hr exposure. Similarly, 96-hr assay showed significant differences with size of oyster $(\mathrm{p}<0.05)$, with small oyster showing lower mortality at all test 
concentrations (Fig. 2c). The 96-hr $\mathrm{LC}_{50}$ value for large oysters was $545 \mathrm{ppm}$ while that for small oysters is $135 \mathrm{ppm}$. The results of this study agree with those of Anderson (1973) and Ranzoni (1973) in that it indicates the high resistance of oysters to crude oil. Ranzoni (1973) reported that oil is toxic to larvae
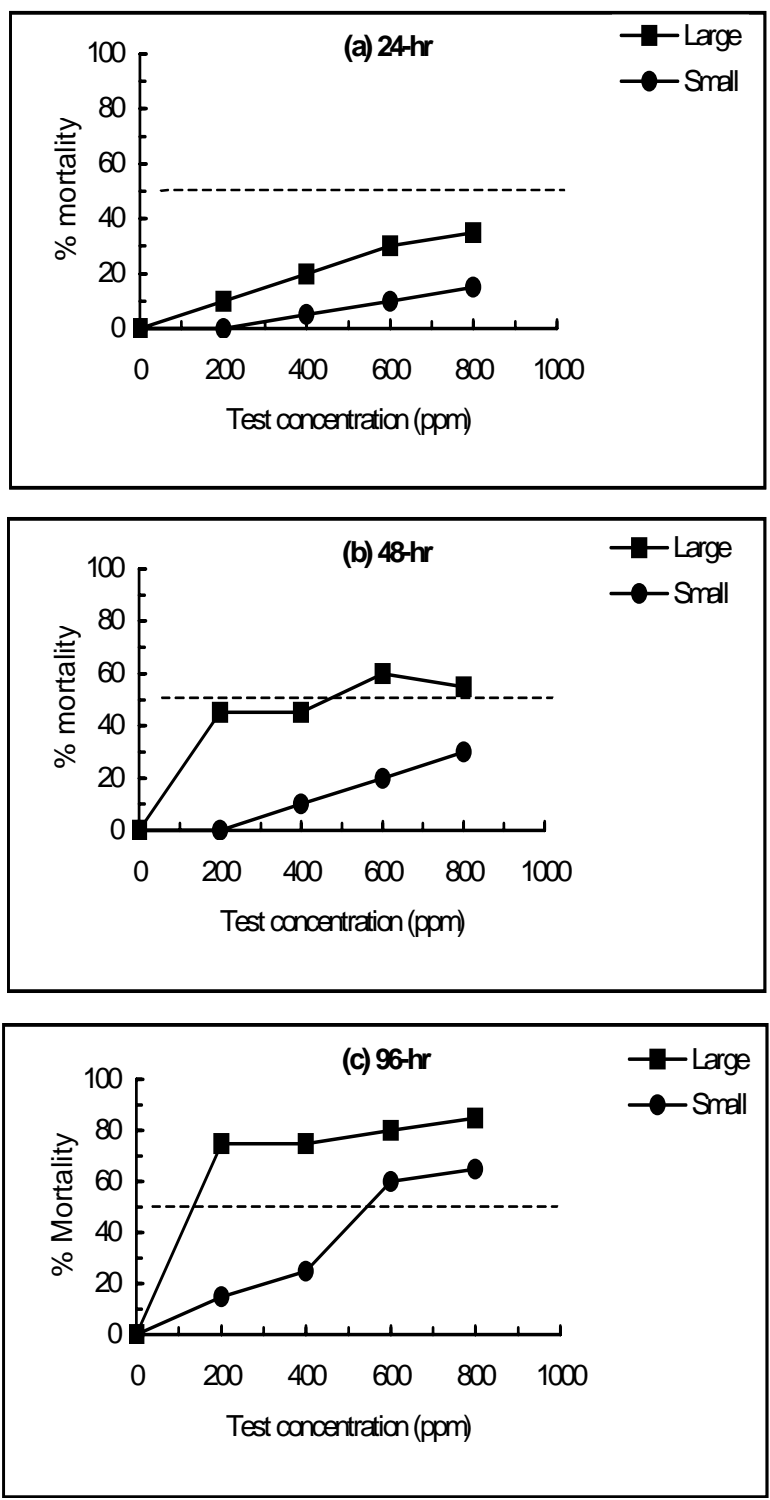

Fig. 2. Relative mortalities (\%) of small $(10-30 \mathrm{~mm})$ and large $(41-60 \mathrm{~mm})$ oysters (Crassostrea gasar) exposed to crude oil in 24-hr, 48-hr and 96-hr bioassays

Generally larvae and early development stages of life cycles of fish and marine invertebrates are the most susceptible to oil pollution (Nelson-Smith, 1977). Anderson (1973) observed that larvae of the America oyster Crassostrea virginica were much more sensitive than adults. However, Noyes et al. (1978) reported on the contrary that oyster larvae did not and eggs of the oyster Crassostrea angulata and Crassostrea gigas only at very high concentrations, which are rarely obtained in the sea. The results of this study show the same for adults of the mangrove oyster, Crassostrea gasar to Nigerian crude oil.

show greater sensitivity to oils when compared to adults. Results of this study consistently showed lower mortalities for small oysters than large ones. Although, significant differences were not obtained in the 24-hr assay period, the Man-Whittney tests showed significantly higher resistance for small oysters in the 48-hr and 96-hr assays. This is further shown by the differences in the 96-h LC $\mathrm{LC}_{50} 135 \mathrm{ppm}$ and $545 \mathrm{ppm}$ for small and large oysters respectively. This indicates that the small oysters are more resistant than large oysters to oil pollution. One reason for such a response is the greater physiological vibrancy of the smaller oysters, which makes them less susceptible to stress in general. The absence of significant difference between the two size classes up to $24 \mathrm{hrs}$ suggests that the protective systems mobilized to deal with the exposures (Roesijadi and Fellingham (1987) initially had similar effects. However, the upper limit of compensatory response was probably lower for the larger oysters leading to a faster failure of the detoxification systems. The implication of the differences in toxic effects with size is that, for purposes of routine use, the size of individuals used should be given due consideration in order to obtain representative data. The more vulnerable group should then be targeted for purposes of setting up regulatory limits. The hardiness of oysters in bioassays has been attributed to their ability to close their shells permanently against toxicants and depuration of toxic substances (Anderson, 1973). As a result, bioassays with oysters (and bivalves in general) may be more suitable if carried out over a longer period.

In this research oil was added to the surface of the water and the water-soluble fraction allowed to dissolve naturally. This is in contrast to an alternative approach (cf. Anderson et al., 1974, Lee and Nicol, 1977), in which case oil is mixed with water by special methods to prepare water soluble fractions so that the exact concentration of the oil causing the observed effects would be known. The method used in this research is, however, considered to be more reminiscent of the natural condition where in the event of an oil spill it is difficult to quantify the concentration of water-soluble fraction dissolved in water. Waves and currents may cause mixing up and enhance dissolution in the sea but no mixing of any sort was carried out except for the small mixing 
action of the bubbling of air into the system. These results could therefore be related to the condition in a considerably calm sea.

Acknowledgements: The assistance of Joshua Abbey in the collection of the specimens is gratefully acknowledged.

\section{REFERENCES}

Ajao, EA; Oyewo, EO; Orekoya, T (1981). The effect of oil formation water on some marine organisms. Proceedings of the International Seminar on the petroleum industry and the $\mathrm{N}$ igerian Environment. FMW\&H/NNPC, PTI Effurum, pp.80-81.

Anderson, JW; Neff, JM; Cox, BA; Tatem, HE; Hightower, GM (1974). The effects of oil on estuarine animals: toxicity, uptake, depuration and respiration. In, Venberg, FH; Venberg, WB (eds) Pollution physiology of marine animals. Academic press, New York, pp.258-310.

Anderson, RD (1973). Effects of petroleum hydrocarbons on the physiology of the American oyster, Crassostrea virginica Gmelin. Ph.D. Thesis, Texas A \& M University, Texas, USA.

Afolabi, ON; deyemi, SA; Imevbore, AMA (1985). Studies of the toxicity of some Nigerian crude oils to some aquatic organisms. Proceedings of the International Seminar on the petroleum industry and the Nigerian Environment. FMW\&H/NNPC, pp. 269-273.

Cowell, EB; Baker, JM; Crapp, GB (1972). The biological effects of oil pollution and oilcleaning materials on littoral communities including salt marshes. In: Rouvio M (ed), Marine Pollution and Sea Life, FAO Tech. Conf., Rome, pp. 359-364.
Craddock, DR (1977). Use and limitations of acute toxicity tests - a review. In: Malins, DC (ed), Effects of petroleum on arctic and subarctic marine environments and organisms. Academic Press, New York, pp.1-93.

Krebs, CT; Burns, KA (1977). Long-term effects of an oil spill on the salt marsh crab Uca pugnax. Science, 197, 484-487.

Lee, WY; Nicol, JAC (1977). The effects of water soluble fraction of No. 2 oil on the survival and behaviour of coastal and oceanic zooplankton. Environ. Pollut., 12, 279-292.

Nelson-Smith, A (1977). Biological consequences of oil spills. In: Lenihan, J. and Fletcher, WW (eds), The Marine Environment, Blackie, London, pp. 44-69.

Noyes, GS; Haskin, HH; Van-Dover, C (1978). Oil and the oyster in Delaware Bay. Proc. Nat Shellfish Ass., 68, 84-85.

Odiete, WO (1999). Environmental Physiology of Animals and Pollution. Diversified Resources, Lagos.

Odu, CTI (1981). Degradation and weathering of crude oil under tropical conditions. Proceedings of the International Seminar on the petroleum industry and the Nigerian Environment. FMW\&H/NNPC, PTI Effurum, pp. 143-154.

Ranzoni, A (1973). Influence of crude oil derivatives and dispersants on larvae. Mar. Pollut. Bull., 4, 7-13.

Roesijadi, G; Fellingham, GW (1987). Influence of $\mathrm{Cu}, \mathrm{Cd}$ and $\mathrm{Zn}$ preexposure on $\mathrm{Hg}$ toxicity in the mussel Mytilus edulis. Can J Fish Aquat Sci, 44, 680-684.

Zar, JH (1984). Biostatistical Analysis. Prentice-Hall, New Jersey. 